\title{
Quality of life after end colostomy without mesh and with prophylactic synthetic mesh in sublay position: one-year results of the STOMAMESH trial
}

\author{
Simon Näverlo ${ }^{1}\left(\mathbb{D} \cdot\right.$ Ulf Gunnarsson $^{1} \cdot$ Karin Strigård $^{1} \cdot$ Pia Näsvall ${ }^{1,2}$
}

Accepted: 25 July 2019 / Published online: 7 August 2019

(C) The Author(s) 2019

\begin{abstract}
Purpose To determine whether prophylactic mesh in a sublay position has an impact on the quality-of-life (QoL) of patients receiving an end colostomy.

Methods One-year follow-up of patients from the STOMAMESH trial, a randomized controlled double-blinded multicenter study. Patients were randomized to either prophylactic synthetic mesh with a cruciform incision in the center, placed in sublay position, or no prophylactic mesh. Patients attended a 1-year visit and responded to the questionnaires EORTC QLQ C-30 and CR-38. The impact of having a mesh on QoL was determined by comparing a group of patients receiving a mesh with a group without. A subgroup analysis was made depending on whether a PSH was clinically present or not.

Results Of the 232 randomized patients, 211 patients reached the 1-year clinical follow-up. The response rate of these 211 patients was 70\%. No differences were seen in global QoL between the groups. Mesh patients reported significantly less stomarelated problems $(p=0.014)$ but more sexual problems in males $(p=0.022)$. When excluding patients with a clinical diagnosis of $\mathrm{PSH}$, the difference in stoma-related problems remained while no significant difference was seen regarding sexual problems in males.

Conclusions When forming an end colostomy, prophylactic synthetic mesh in a sublay position did not affect global QoL at 1year follow-up, but stoma-related problems were fewer even in the presence of a clinically diagnosed PSH.
\end{abstract}

Trial registration NCT00917995

Keywords Quality-of-life · Mesh · Parastomal hernia · Prophylaxis

\section{Introduction}

The presence of a stoma has a negative impact on qualityof-life (QoL) [1-3]. Complications arising from a stoma are common and varied; parastomal hernia (PSH) being one of the most frequent and important of these [4]. Other examples are bulging, stenosis, intestinal obstruction, retraction, prolapse, and skin complications [4-7]. Stomarelated problems are both physical and psychological $[8$, 9]. As a result, not only do these complications lead to

Simon Näverlo

simon.naverlo@umu.se

1 Department of Surgical and Perioperative Sciences, Surgery, Umeå University, SE-901 88 Umeå, Sweden

2 Sunderby Research Unit, Umeå University, Luleå, Sweden patient discomfort and dissatisfaction but also a wellfunctioning stoma in the eye of the clinician may cause problems regardless.

Previous studies have described problems such as social restriction, difficulty in stoma dressing, appliance leakage, pain, limitations of activity, cosmetic problems, and difficulties with clothing [10-12]. If a PSH or bulge is present, the patient's quality of life is reduced even more [3].

The reported frequency of PSH varies between a few and $78 \%[5,13-15]$. One obvious reason for this variability is the difficulty in diagnostics and divergent definition of a PSH [16]. PSH repair is associated with high rates of recurrence, morbidity, and mortality $[17,18]$. Of the poor alternatives currently available, surgical repair using mesh has become the procedure most employed $[19,20]$. The use of mesh in hernia repair in other locations in the abdominal wall, however, has been associated with higher complication rate, risk for fistula formation, and pain [21-23]. 
Various surgical strategies have been tried in an attempt to prevent PSH, but none has managed to reduce the frequency $[5,24]$. Prophylactic placement of a mesh to reduce the frequency of PSH has been proposed. Smaller randomized controlled trials (RCT) and a metaanalysis have indicated that mesh placement decreases the risk for PSH formation [18]. Prophylactic onlay, sublay, and laparoscopic intraperitoneal mesh techniques have been used when creating a stoma, but mesh position has not been shown to have an effect on the recurrence rate $[18,25]$. Controlled follow-up studies have seldom reported morbidity and quality-of-life after prophylactic mesh placement. This aspect is important when evaluating the use of prophylactic mesh since smaller studies have shown a high frequency of late mesh complications [11].

In 2017, we published an RCT (STOMAMESH) assessing the effectiveness of prophylactic mesh in sublay position with a cruciform incision in the center in the prevention of PSH [26]. Contrary to previous studies, no significant differences in the frequency of clinically or radiologically detectable PSH were seen between the mesh and non-mesh groups after 1 year. Nor were there any differences between the groups regarding surgical complications or other complications such as thrombosis or pneumonia, at 1 month. The rate of clinically diagnosed PSH was close to $30 \%$ in both groups $(30 \%$ in non-mesh vs $29 \%$ in mesh).

Colorectal cancer is a common reason for forming an end colostomy, and recurrence rates for colorectal cancer have decreased substantially $[27,28]$. This has led research to focus instead on other outcomes such as QoL, an outcome that is now considered when evaluating any form of treatment [29].

Validated tools for the assessment of QoL have been constructed both for general health in cancer patients and diseasespecific symptoms in colorectal cancer [30,31].

This study was a 1-year follow-up of a randomized controlled trial comparing prophylactic synthetic mesh in sublay position with no mesh when forming an end colostomy. Results regarding PSH rate and early complications as primary and secondary outcomes have already been published [26]. In this study on the same patient cohort, we compared global QoL assessed with EORTC and QLQ C-30 as well as differences in other symptoms and functional scales in C-30 and CR-38, between patients with and without a mesh. In a subgroup analysis, we also compared the same outcomes dividing the population based on whether clinically diagnosed PSH was present or not.

The hypothesis in the original study was that a sublay mesh around the end colostomy decreases the risk for PSH. This study reports the impact of prophylactic mesh on QoL 1 year after stoma formation.

\section{Method}

This was a 1-year follow-up of a randomized controlled double-blinded multicenter study (STOMAMESH), with QoL as outcome. Patients were randomized to either prophylactic synthetic mesh with a cruciform incision in the center placed in sublay position around the stoma or no prophylactic mesh. The study was registered at ClinicalTrials.gov (Identifier: NCT00917995) and adhered to the CONSORT 2010 criteria for RCTs.

All patients that were planned for a permanent end colostomy and who met all inclusion and exclusion criteria were eligible for participation (Table 1). The surgical technique used has been described in a previously published paper by Odensten et al. [26]. One year after index surgery, patients were asked to answer QoL questionnaires, and clinical assessment of any late complication or development of PSH was performed by a surgeon blinded to the technique used. The questionnaires were sent out by mail prior to the follow-up visit and the patient requested to fill in and hand over the completed questionnaire at the follow-up visit. If the questionnaires had not been filled in, patients were given the opportunity to answer the questionnaires at the time of the visit. All responders were included in this study. A subgroup analysis was also performed based on whether a clinical diagnosis of PSH was made or not. Results from the original study showed no significant difference in rate between clinically diagnosed and CT-scan diagnosed PSH [26]. This, together with the fact that the CT-scan was performed in the supine position while the clinical assessment in this study was performed in the upright position, motivated our choice to use the clinical diagnosis.

To assess the research question, answers from two validated questionnaires were used. These questionnaires were developed by the European Organization of Research and Treatment of Cancer (EORTC) and are normally answered together since they focus on different aspects of QoL. The EORTC QLQ-C30 (third version) is often referred to as the "core questionnaire," consisting of a broad spectrum of questions incorporating physical, social, and emotional aspects of cancer [30]. The C-30 contains 30 questions, all paired into

Table 1 Inclusion and exclusion criteria for the STOMAMESH study

\begin{tabular}{ll}
\hline Inclusion criteria & Exclusion criteria \\
\hline No previous stoma & Expected survival less than 3 years \\
Older than 18 years & Fecal peritonitis \\
& No informed consent
\end{tabular}

Quality of life after end colostomy without mesh and with prophylactic synthetic mesh in sublay position: one-year results of the STOMAMESH trial, International Journal of Colorectal Disease, Simon Näverlo, Ulf Gunnarsson, Karin Strigård, Pia Näsvall, Department of Surgical and Perioperative Sciences, Umeå University, simon.naverlo@umu.se 
different "scales" depending on the affinity among the questions. It contains 1 global QoL measure, 5 functional scales, and 9 symptom scales. The EORTC QLQ CR-38 comprises 38 questions; all disease-specific for colorectal cancer. As in C-30, the questions in CR-38 are also grouped into scales, 4 functional scales and 8 symptom scales [31]. The functional scales comprise body image, future perspective, sexual functioning, and sexual enjoyment. The symptom scales cover urinary, gastrointestinal, defecation and sexual symptoms, chemotherapy side-effects, weight loss, and symptoms due to stoma-related problems. Since all patients included had a permanent end colostomy, no questions regarding defecation were answered.

Answers to the questionnaires were converted to scale scores ranging from 0 to 100 in accordance with the EORTC scoring manual [32]. Global QoL scale, functional scale, and symptom scale scores are interpreted differently. A high functional scale or the global QoL scale score represents a higher degree of functioning or level of QoL, whereas a high symptom scale score represents more symptoms or problems.

The power calculation for the original trial was designed to assess PSH versus no PSH and was based on the assumption of a 20\% PSH rate without and 5\% with a prophylactic mesh in sublay position. The de facto power was $91 \%$ [26].

\section{Statistics}

For conversion of responses to EORTC QLQ CR-38 and C-30 into appropriate scales, SPSS v.18.0 (IBM Corp., Armonk, NY, USA) was used. All other calculations were made using STATA version 13.1 (STATACorp LP, College Station, TX, US). When comparing means, the independent Student's $t$ test was used. Chi2 or Fischer's exact test was used in categorical outcomes ( $\leq 5$ Fischer's exact test, otherwise Chi2). A $p$ value below 0.05 was considered significant.

\section{Compliance with ethical standards}

All patients gave written informed consent to be included in the study. The study was approved by the Regional Ethics Committee at Umeå University, Sweden (DNR 07-081M). The study protocol adhered to the principles of the Helsinki Declaration. The authors declare that they have no conflicts of interest in this study.

\section{Results}

Of the 232 patients who were randomized, 211 (91\%) patients attended the 1-year clinical follow-up. The reasons for loss of 21 patients to 1-year clinical follow-up are shown in a CONSORT diagram (Fig. 1): refusal to participate $(n=9)$; death $(n=7)$; surgical complication $(n=3)$; dementia $(n=1)$; and progression of disease $(n=1)$. Of the 211 patients remaining, 148 answered the QoL surveys, yielding a response rate of $70 \%$.

Median age was 71 years, and 59\% were male. Apart from a higher percentage of male responders in the mesh group $(p=0.020)$, there were no significant differences in baseline characteristics (Table 2). All responders to the questionnaires were operated electively. Clinically diagnosed PSH was present in 45 of the 148 (30\%) patients. There were no significant differences between the groups regarding occurrence of PSH, bulging only, stenosis, prolapse, or stoma dressing problems.

A difference in score of 5.9 in favor of mesh was also seen for global QoL in the generic instrument QLQ C-30. This difference, however, was not significant $(p=0.101)$. When comparing differences in other symptom and functional scores in QLQ C-30, mesh patients scored significantly higher for "emotional functioning" (7.5 higher, $p=0.025)$ and "cognitive functioning" (5.9 higher, $p=0.015$ ) (Fig. 2). When patients with a clinically diagnosed PSH $(n=45)$ were excluded from the analysis, these differences remained significant with mesh patients scoring higher.

When comparing symptom and functional scores using the colorectal cancer-specific instrument QLQ CR-38, the mesh group reported significantly less stoma-related problems (difference 8.4, $p=0.014$ ). In the same questionnaire, the mesh group also reported more sexual problems in males (difference 17.4, $p=0.022$ ). No other significant differences were seen (Fig. 3). When patients with a clinically diagnosed PSH $(n=45)$ were excluded from this analysis, the difference in stoma-related problems remained while no significant difference was seen regarding sexual problems in males.

In the subgroup analysis on patients with a clinically diagnosed PSH and patients without, there were no significant differences in baseline data. Using the generic QoL instrument QLQ-C30 and comparing PSH with no PSH ( $n=45$ vs. 105 ), no difference in global QoL, was seen. In the QLQ-C30 symptom and functional scales, the PSH group reported more constipation than patients with no PSH (score difference 6.3; $p=$ 0.023 ); no other significant differences were seen. In the disease-specific QLQ CR-38, no significant differences between the groups were seen. The PSH group reported numerically but not significantly $(p=0.39)$ more stoma-related problems.

In the QLQ-C30 form responses, missing observations varied between 0 and $2(0-1 \%)$ for all scales. In the CR 38 form replies, missing scales assessing non-sexual problems varied between 1 and $4(0.5-3 \%)$. For gender-neutral questions on sexual problems, i.e., sexual functioning and sexual enjoyment, $14(9 \%)$ and $110(74 \%)$ cases were missing respectively. In the gender-specific questions, i.e., male sexual problems and female sexual problems, 12 (14\%) and 49 (82\%) scales were missing respectively. 
Fig. 1 Consort diagram of the 148 patients included in the QoL analysis. Quality of life after end colostomy without mesh and with prophylactic synthetic mesh in sublay position: one-year results of the STOMAMESH trial, International Journal of Colorectal Disease, Simon Näverlo, Ulf Gunnarsson, Karin Strigård, Pia Näsvall, Department of Surgical and Perioperative Sciences, Umeå University, simon.naverlo@umu.se

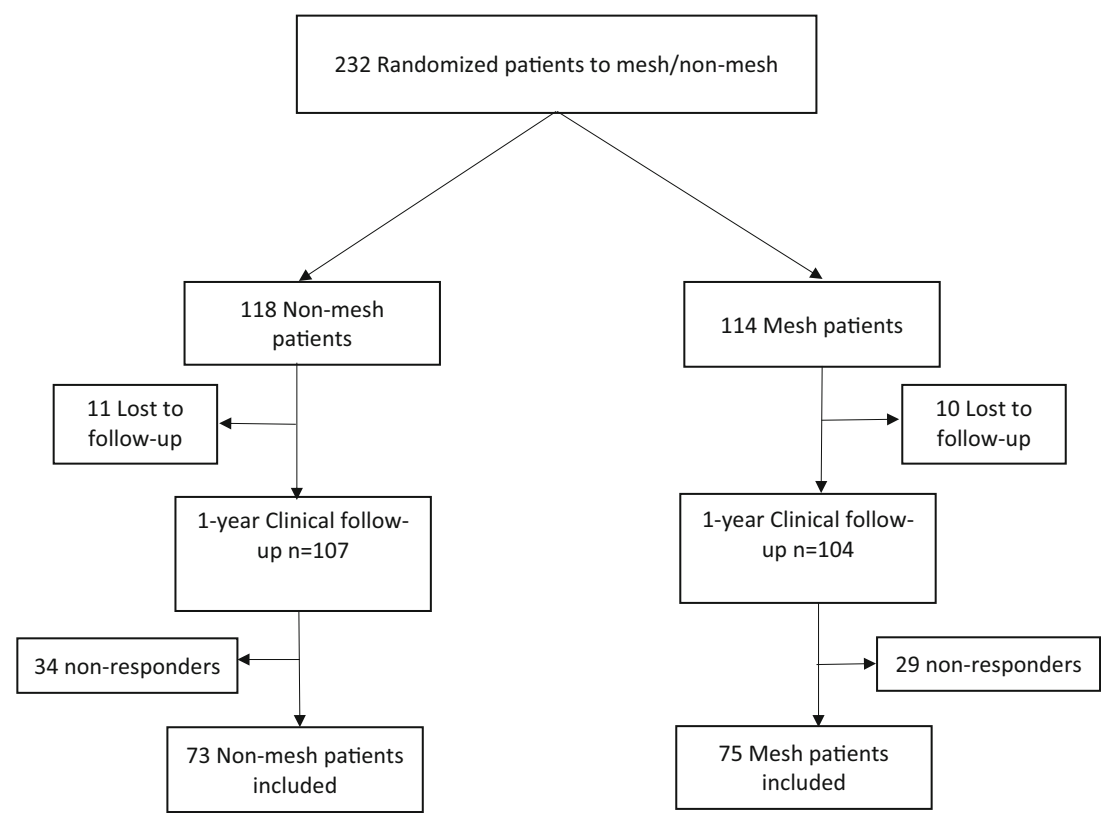

\section{Discussion}

The use of a prophylactic synthetic mesh in sublay position when creating an end colostomy did not have an impact on postoperative global QoL. However, mesh patients reported significantly less stoma-related problems compared to those who did not receive a mesh in this randomized controlled study. The difference in the number of stoma-related problems remained significant even when patients with a clinically diagnosed PSH were excluded from the analysis. Among those responding to the questionnaires, there were no differences in the numbers of PSH or bulging only seen between the mesh
Table 2 Basic demographic data for all responders of the QoL questionnaires

\begin{tabular}{llll}
\hline$n=148$ & Non-mesh, $n=73$ & Mesh $n=75$ & $p$ value \\
\hline Age, years, range & $70(36-88)$ & $71(50-87)$ & 0.559 \\
Male (\%) & $37(51 \%)$ & $51(68 \%)$ & $0.032 *$ \\
ASA & & $13(17 \%)$ & 0.297 \\
ASA 1 $(n=21)$ & $8(11 \%)$ & $47(63 \%)$ & 0.790 \\
ASA 2 $n=93)$ & $46(63 \%)$ & $15(20 \%)$ & 0.565 \\
ASA 3 $n=32)$ & $17(23 \%)$ & 0 & 0.367 \\
Missing value & 2 & $8(11 \%)$ & \\
Smoker & $4(5 \%)$ & 4 & 0.361 \\
Missing value & 4 & $26.2(16.7-37.8)$ & \\
BMI, range & $26.9(18.5-43.7)$ & 1 & 0.239 \\
Missing value & 2 & $70(93 \%)$ & 0.249 \\
Cancer & $64(88 \%)$ & $313(70-616)$ & \\
Operation time, min, range & $292(98-625)$ & 5 & 0.871 \\
Missing value & 4 & $12(4-44)$ & \\
Length of stay, days, range & $12(4-44)$ & 2 & \\
Missing value & 5 & & \\
\hline
\end{tabular}

Asterisk indicates $p<0.05$. Mean values are shown for age, BMI, operation time, and length of stay. $p$ values from $t$ test when comparing means. When comparing a categorical outcome, $p$ values from chi $^{2}$ or Fischer's exact test. Because of missing values, the sum of the distribution in ASA-classification in the non-mesh group does not reach $100 \%$

Quality of life after end colostomy without mesh and with prophylactic synthetic mesh in sublay position: oneyear results of the STOMAMESH trial, International Journal of Colorectal Disease, Simon Näverlo, Ulf Gunnarsson, Karin Strigård, Pia Näsvall, Department of Surgical and Perioperative Sciences, Umeå University, simon.naverlo@umu.se 


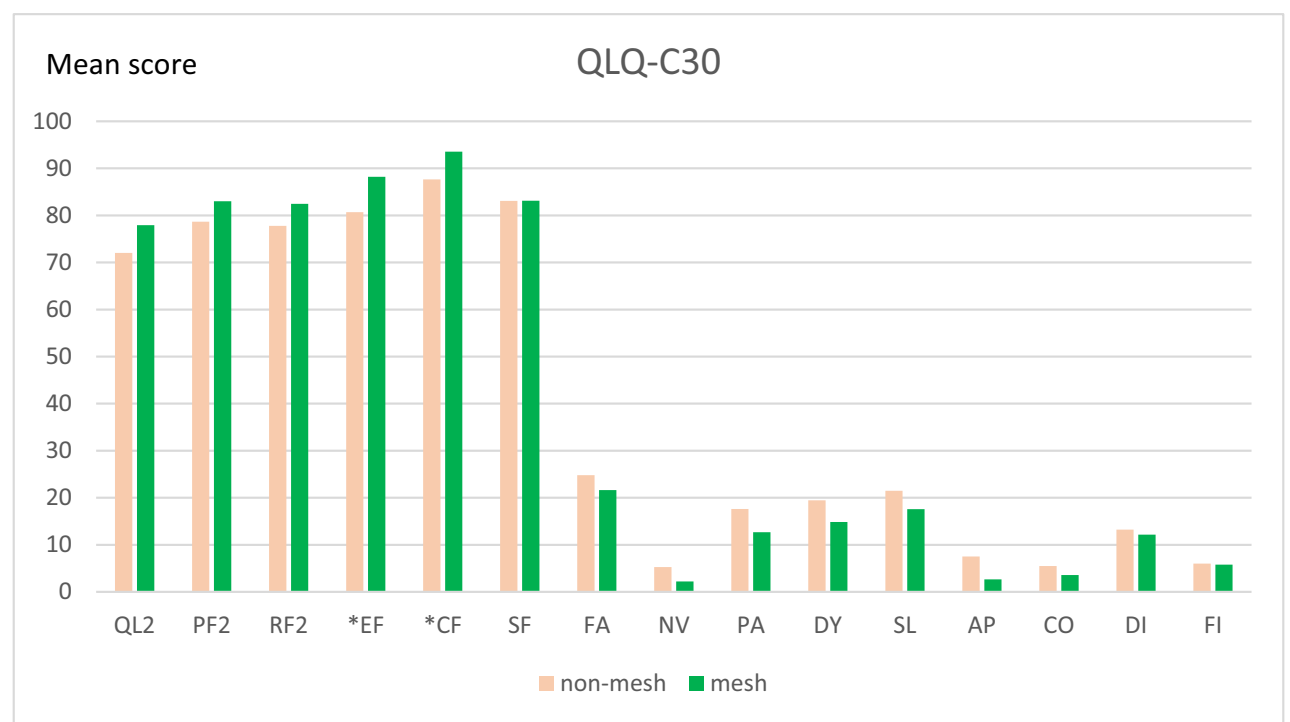

Fig. 2 Differences in mean scores between non-mesh and mesh groups in generic quality of life assessed with EORTC QLQ C-30. Asterisk indicates $p<0.05$. A high value in functional scales indicates high level of functioning while a high value in symptom scales indicates high level or more symptoms. Functional scales: QL2 global health status/QoL, PF2 physical functioning, RF2 role functioning, EF emotional functioning, $\mathrm{CF}$ cognitive functioning, SF social functioning. Symptom scales: FA

and non-mesh patients. Furthermore, there were no differences in occurrence of other stoma-related complications such as stenosis, prolapse, and dressing problems. fatigue, NV nausea and vomiting, PA pain, DY dyspnea, SL insomnia, AP appetite loss, CO constipation, DI diarrhea, FI financial difficulties. Quality of life after end colostomy without mesh and with prophylactic synthetic mesh in sublay position: one-year results of the STOMAMESH trial, International Journal of Colorectal Disease, Simon Näverlo, Ulf Gunnarsson, Karin Strigård, Pia Näsvall, Department of Surgical and Perioperative Sciences, Umeå University, simon.naverlo@umu.se

Together, these results suggest that prophylactic synthetic mesh in sublay position significantly reduces stoma-related problems in ways other than reduction in any of the above-

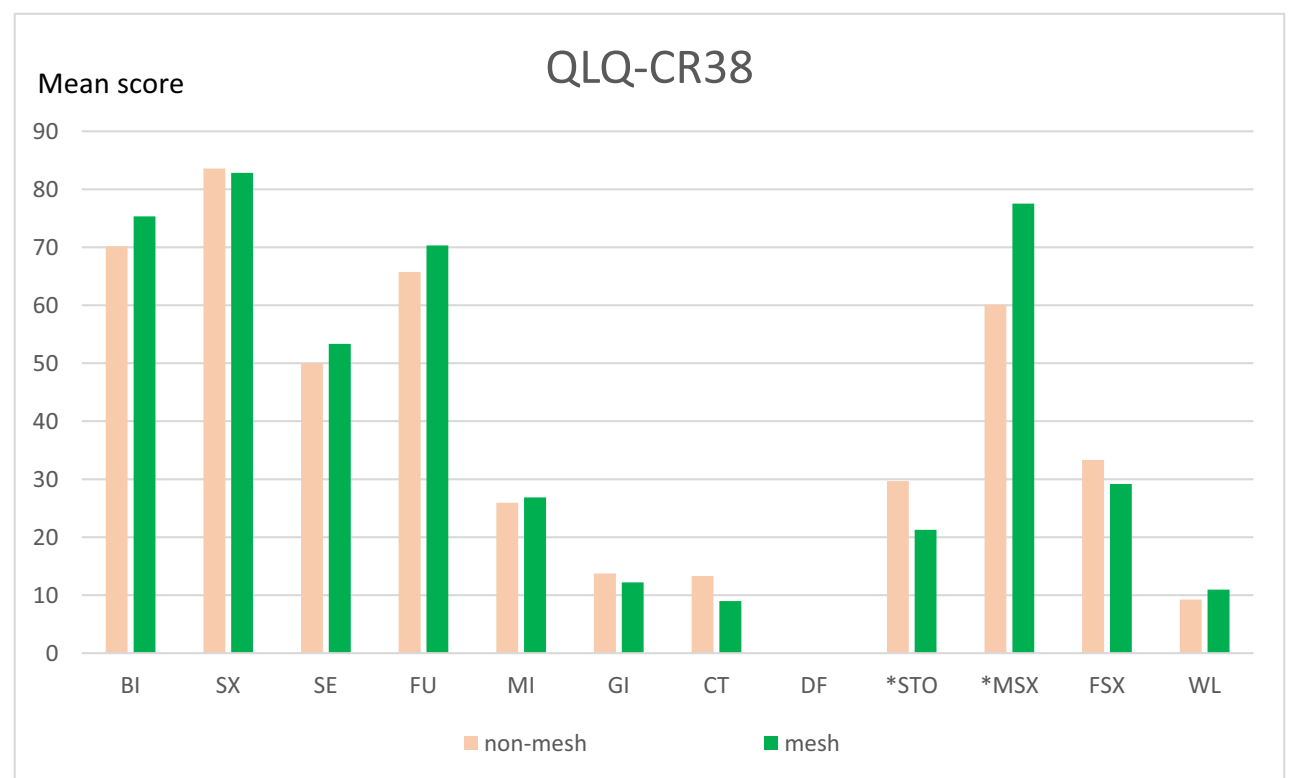

Fig. 3 Differences in mean scores between non-mesh and mesh groups in colorectal cancer-specific quality-of-life assessed with EORTC QLQ CR38. Asterisk indicates $p<0.05$. A high value in functional scales indicates high level of functioning while a high value in symptom scales indicates higher level or more symptoms. Function scales: BI body image, SX sexual functioning, SE sexual enjoyment, FU future perspective. Symptom scales: MI micturition problems, GI gastrointestinal symptoms, CT chemotherapy side- effects, DF defecation problems (not applicable in this study, only stoma patients), STO stoma-related problems, MSX male sexual problems, FSX female sexual problems, WL weight loss. Quality of life after end colostomy without mesh and with prophylactic synthetic mesh in sublay position: one-year results of the STOMAMESH trial, International Journal of Colorectal Disease, Simon Näverlo, Ulf Gunnarsson, Karin Strigård, Pia Näsvall, Department of Surgical and Perioperative Sciences, Umeå University, simon.naverlo@umu.se 
mentioned stoma-related complications. The score difference in favor of mesh patients regarding stoma-related problems was close to 10 ; a difference above 5 is considered clinically relevant and differences between 10 and 20 are considered "moderate" [33]. Hence, the positive effect of using a prophylactic mesh is something that cannot be ignored, but its use must be considered critically.

Besides the difference in scores in favor of mesh implantation seen with the colorectal cancer-specific symptom questions in QLQ CR-38, similar differences were seen in responses to the generic QLQ C-30 form. Here, mesh patients reported higher scores for "emotional functioning" and "social functioning." As was the case with stoma-related problems, the superior scores from the QLQ CR-30 and 38 remained significant when patients with a clinically diagnosed PSH were excluded from the analysis. This strengthens the significant trend of the results in this study that mesh patients show superior ratings compared to those with no mesh, even in the absence of a PSH or other common stoma-related complications. The obvious counter question to these results is how would a sublay mesh affect stoma-related problems negatively when no differences is seen in stoma-related complications between the groups? One possible explanation is that the mesh results in a stabilizing effect on the part of the abdominal wall involving the stoma, facilitating bag appliance and/or stomal care. Another factor that could possibly explain this difference is that a prophylactic mesh could limit the size of a PSH should it occur, but this was not assessed in this study.

Contrary to these differences in favor of mesh implantation, no difference was seen in global quality-of-life, and male mesh patients reported significantly more sexual problems than those with no mesh. This difference disappeared when patients with a PSH were excluded from the analysis. This suggests that the mesh itself constitutes an aggravating factor of sexual problems in males, but only when a PSH is present. This is possibly due to a chafing feeling which is only present when the anatomy of the stoma is disrupted with displacement of the mesh, as is the case when a PSH is present.

We have previously published data showing that placement of a reinforcement prophylactic synthetic mesh with a cruciform incision in the center placed in sublay position at index surgery has no effect on the occurrence of PSH [26]. This, together with the finding of sexual problems in males when a PSH is present, could advocate a restrictive attitude towards prophylactic mesh placement in males. Previously published data showed no difference in baseline regarding gender in the STOMAMESH study population [26]. In this follow-up study, however, there was a significant overweight of male responders in the mesh group. One possible reason for this could be report bias, where men with sexual problems tended to respond more frequently than men in the non-mesh group with no such problems, in order to let those responsible for the study know about their problems.
In a recent meta-analysis [18] of results from RCTs studying the use of prophylactic mesh for PSH prevention, only two out of ten studies reported using a validated QoL questionnaire $[34,35]$. Fleshman et al. used a stoma-specific QoL questionnaire [35], and Brandsma et al. used the SF-36 and Von Korff's questionnaire for grading the severity of chronic pain [34]. SF-36 is an instrument assessing generic QoL similar to the QLQ C-30, and Von Korffs is an instrument that only assesses chronic pain. The choice of EORTC QLQ C-30 and CR-38 seemed more reasonable to us because these combine generic QoL in the C-30 and colorectal cancer-specific QoL in the CR-38 questionnaire. Fleshman et al., using a stoma-specific questionnaire only, did not consider other frequently occurring symptoms of colorectal disease, which could be seen as a weakness. The other studies did not include data from validated QoL surveys, and hence, no conclusions regarding QoL could be made [13, 36-41].

Furthermore, the present population was divided between patients with a clinically diagnosed PSH and those with no PSH to assess the impact a PSH has on QoL. Interestingly, no differences could be seen in colorectal cancer-specific symptoms as assessed by the CR-38. In the generic C-30, patients with a PSH reported a greater problem with constipation. Pain is a major symptom of PSH [10], and one could speculate that opioid treatment with secondary constipation played a part in this difference. Previous results published by our research group showed that stoma patients with a PSH or bulge reported inferior scores in several symptom and functional scales [3]. That study was a cross-sectional study on QoL in rectal cancer patients and included far more patients than the present study, probably explaining this contradiction. It is unlikely that PSH has no effect on colorectal cancer-specific symptoms, so the reason for the similarity in symptoms between the groups in this study may have been the result of insufficient power to detect a difference between patients with a PSH and those without. Division of the study population between PSH and no PSH resulted in a skewed distribution compared to division between mesh and no mesh (45 vs 103 and 75 vs 73 resp.). This difference in size of the groups could be a reason for the inability to detect a difference between patients with and those without a PSH whereas differences could be seen between patients with or without a mesh regardless of PSH.

That the sample size was not calculated to detect differences in QoL is a major weakness of this study. As mentioned in the previous paragraph, this can lead to an inability to detect differences between the groups. Another weakness is the number of dropouts, 148 responders of 232 randomized patients. Furthermore, conclusion can only be drawn from the surgical method used, not other ways of preventing PSH.

The overall completeness of responses to the core questionnaire $\mathrm{C}-30$ was high $(0-1 \%$ missing cases). In the colorectal cancer-specific survey, completeness was slightly lower (0.5- 
$3 \%$ missing cases), at least for questions not concerning sexual problems. The frequency of unanswered questions on sexual matters was as high as $74 \%$ regarding sexual enjoyment and $82 \%$ regarding female sexual problems. This response pattern is not unique and other studies using the EORTC instrument report the same tendency [42]. In the case of female sexual problems and sexual enjoyment, it is therefore obvious that no conclusion can be reached. On the other hand, compared to Herrle et al., the $86 \%$ completeness regarding answers on male sexual problems in this study is distinctly higher, so our results regarding an association between placement of a prophylactic mesh and male sexual problems could be relevant. Nevertheless, there is of course a possibility that there may be no clinical correlation despite statistical ditto.

This is the largest RCT to date in this field, and a strength is that it was performed as a multicenter study blinded to both patients and clinicians [38, 40, 43]. Apart from being a followup of the original study, these results are of importance in their own right [44]. This study only comprises data from a 1-year follow-up. Even though most PSH develop within the first year, they can occur up to 30 years later. Long-term followup of this cohort is therefore of great importance to increase the knowledge of the impact of a prophylactic synthetic mesh, both on its preventive effect on PSH development but also to answer the question of its effect on QoL. Development of new improved ways of prevention and treatment for PSH is of importance. A preventive measure that reduce the incidence of PSH will likely improve QoL, and even if an RCT with QoL as its main outcome might be redundant, it remains an endpoint important to assess when developing new surgical methods.

The most recently published European guidelines, published prior to the STOMAMESH trial, stated a strong recommendation towards the use of a prophylactic synthetic mesh during the construction of a permanent end colostomy [45]. Thus, in order to reduce the incidence of parastomal hernia. The studies underlying this recommendation consisted mostly of an open surgical approach with a hole in the center of the prosthesis placed retromuscular. Only two of the included studies used a key-hole mesh. Furthermore, most studies used a synthetic mesh while only two of the included studies used a biological mesh. The reasoning on the effect on QoL in this study could of course only be applied on patients operated with the technique used, a synthetic mesh placed in a sublay position with a cruciform incision in the middle.

In this study, we found that patients receiving a prophylactic synthetic mesh in a sublay position with their end colostomy report significantly fewer stoma-related problems. However, this positive effect appears to depend on factors other than the prevention of a PSH or other common stomarelated complications. Nevertheless, a moderate decrease in stoma-related problems without any significant impact on global quality-of-life cannot be considered a strong argument in favor of mesh placement when forming an end colostomy.

\section{Conclusions}

The use of prophylactic synthetic mesh with a cruciform incision in the center placed in a sublay position when forming an end colostomy does not improve global QoL after surgery, but it significantly reduces stoma-related problems, regardless of whether a PSH is present or not. However, the positive impact of prophylactic mesh seen in this study is not sufficient to constitute an argument for routine use in stoma formation.

Acknowledgments The authors would like to thank research nurse Lisa Eskilsson, Department of Surgery, Sunderby Hospital, Region Norrbotten and all hospitals participating in the study.

Funding Open access funding provided by Umea University. Financial support was received from the Swedish Research Council 214-7196 and the Department of Research and Development, Region Norrbotten, Sweden.

\section{Compliance with ethical standards}

Conflict of interest The authors declare that they have no conflicts of interest.

Ethical approval All procedures performed in studies involving human participants were in accordance with the ethical standards of the Regional Ethics Committee at Umeå University, Sweden (DNR 07-081M) and with the 1964 Helsinki declaration and its later amendments or comparable ethical standards.

Open Access This article is distributed under the terms of the Creative Commons Attribution 4.0 International License (http:// creativecommons.org/licenses/by/4.0/), which permits unrestricted use, distribution, and reproduction in any medium, provided you give appropriate credit to the original author(s) and the source, provide a link to the Creative Commons license, and indicate if changes were made.

\section{References}

1. Tsunoda A, Nakao K, Hiratsuka K, Tsunoda Y, Kusano M (2007) Prospective analysis of quality of life in the first year after colorectal cancer surgery. Acta Oncol 46(1):77-82

2. Tsunoda A, Tsunoda Y, Narita K, Watanabe M, Nakao K, Kusano M (2008) Quality of life after low anterior resection and temporary loop ileostomy. Dis Colon Rectum 51(2):218-222. https://doi.org/ 10.1007/s10350-007-9101-7

3. Näsvall P, Dahlstrand U, Löwenmark T, Rutegård J, Gunnarsson U, Strigård K (2017) Quality of life in patients with a permanent stoma after rectal cancer surgery. Qual Life Res 26(1):55-64. https://doi. org/10.1007/s11136-016-1367-6

4. Londono-Schimmer EE, Leong AP, Phillips RK (1994) Life table analysis of stomal complications following colostomy. Dis Colon Rectum 37(9):916-920 
5. Carne PW, Robertson GM, Frizelle FA (2003) Parastomal hernia. Br J Surg 90(7):784-793. https://doi.org/10.1002/bjs.4220

6. Robertson I, Leung E, Hughes D, Spiers M, Donnelly L, Mackenzie I, Macdonald A (2005) Prospective analysis of stomarelated complications. Color Dis 7(3):279-285. https://doi.org/10. 1111/j.1463-1318.2005.00785.x

7. Caricato M, Ausania F, Ripetti V, Bartolozzi F, Campoli G, Coppola R (2007) Retrospective analysis of long-term defunctioning stoma complications after colorectal surgery. Color Dis 9(6):559-561. https://doi.org/10.1111/j.1463-1318.2006. 01187.x

8. Kasparek MS, Hassan I, Cima RR, Larson DR, Gullerud RE, Wolff BG (2012) Long-term quality of life and sexual and urinary function after abdominoperineal resection for distal rectal cancer. Dis Colon Rectum 55(2):147-154. https://doi.org/10.1097/DCR. 0b013e31823d2606

9. Åkesson O, Syk I, Lindmark G, Buchwald P (2012) Morbidity related to defunctioning loop ileostomy in low anterior resection. Int J Color Dis 27(12):1619-1623. https://doi.org/10.1007/s00384012-1490-y

10. Krogsgaard M, Pilsgaard B, Borglit TB, Bentzen J, Balleby L, Krarup PM (2016) Symptom load and individual symptoms before and after repair of parastomal hernia: a prospective single centre study. Color Dis 19:200-207. https://doi.org/10.1111/codi.13403

11. Wara P, Andersen LM (2011) Long-term follow-up of laparoscopic repair of parastomal hernia using a bilayer mesh with a slit. Surg Endosc 25(2):526-530. https://doi.org/10.1007/s00464-010-12059

12. Ripoche J, Basurko C, Fabbro-Perray P, Prudhomme M (2011) Parastomal hernia. A study of the French federation of ostomy patients. J Visc Surg 148(6):e435-e441. https://doi.org/10.1016/j. jviscsurg.2011.10.006

13. Jänes A, Cengiz Y, Israelsson LA (2009) Preventing parastomal hernia with a prosthetic mesh: a 5-year follow-up of a randomized study. World J Surg 33(1):118-121; discussion 22-3. https://doi. org/10.1007/s00268-008-9785-4

14. Cingi A, Solmaz A, Attaallah W, Aslan A, Aktan AO (2008) Enterostomy closure site hernias: a clinical and ultrasonographic evaluation. Hernia. 12(4):401-405. https://doi.org/10.1007/ s10029-008-0355-3

15. Cheung MT, Chia NH, Chiu WY (2001) Surgical treatment of parastomal hernia complicating sigmoid colostomies. Dis Colon Rectum 44(2):266-270

16. Gurmu A, Matthiessen $\mathrm{P}$, Nilsson S, Påhlman L, Rutegård J, Gunnarsson U (2011) The inter-observer reliability is very low at clinical examination of parastomal hernia. Int J Color Dis 26(1):89 95. https://doi.org/10.1007/s00384-010-1050-2

17. Helgstrand F, Rosenberg J, Kehlet H, Jorgensen LN, Wara P, Bisgaard T (2013) Risk of morbidity, mortality, and recurrence after parastomal hernia repair: a nationwide study. Dis Colon Rectum 56(11):1265-1272. https://doi.org/10.1097/DCR. 0b013e3182a0e6e2

18. Cross AJ, Buchwald PL, Frizelle FA, Eglinton TW (2017) Metaanalysis of prophylactic mesh to prevent parastomal hernia. Br J Surg 104(3):179-186. https://doi.org/10.1002/bjs.10402

19. Stelzner S, Hellmich G, Ludwig K (2004) Repair of paracolostomy hernias with a prosthetic mesh in the intraperitoneal onlay position: modified Sugarbaker technique. Dis Colon Rectum 47(2):185-191

20. Rubin MS, Schoetz DJ, Matthews JB (1994) Parastomal hernia. Is stoma relocation superior to fascial repair? Arch Surg 129(4):413418 discussion 8-9

21. Winsnes A, Haapamäki MM, Gunnarsson U, Strigård K (2016) Surgical outcome of mesh and suture repair in primary umbilical hernia: postoperative complications and recurrence. Hernia. 20(4): 509-516. https://doi.org/10.1007/s10029-016-1466-x
22. Leber GE, Garb JL, Alexander AI, Reed WP (1998) Long-term complications associated with prosthetic repair of incisional hernias. Arch Surg 133(4):378-382

23. Halm JA, Heisterkamp J, Veen HF, Weidema WF (2005) Longterm follow-up after umbilical hernia repair: are there risk factors for recurrence after simple and mesh repair. Hernia. 9(4):334-337. https://doi.org/10.1007/s10029-005-0010-1

24. Hotouras A, Murphy J, Thaha M, Chan CL (2013) The persistent challenge of parastomal herniation: a review of the literature and future developments. Color Dis 15(5):e202-e214. https://doi.org/ 10.1111/codi. 12156

25. Helgstrand F, Gögenur I, Rosenberg J (2008) Prevention of parastomal hernia by the placement of a mesh at the primary operation. Hernia. 12(6):577-582. https://doi.org/10.1007/s10029-0080387-8

26. Odensten $\mathrm{C}$, Strigård $\mathrm{K}$, Rutegård J, Dahlberg M, Ståhle U, Gunnarsson U, Näsvall P (2017) Use of prophylactic mesh when creating a colostomy does not prevent parastomal hernia: a randomized controlled trial-STOMAMESH. Ann Surg 269:427-431. https://doi.org/10.1097/SLA.0000000000002542

27. Påhlman L, Glimelius B (1984) Local recurrences after surgical treatment for rectal carcinoma. Acta Chir Scand 150(4):331-335

28. Påhlman L, Bohe M, Cedermark B, Dahlberg M, Lindmark G, Sjödahl R, Öjerskog B, Damber L, Johansson R (2007) The Swedish rectal cancer registry. Br J Surg 94(10):1285-1292. https://doi.org/10.1002/bjs.5679

29. Rauch P, Miny J, Conroy T, Neyton L, Guillemin F (2004) Quality of life among disease-free survivors of rectal cancer. J Clin Oncol 22(2):354-360. https://doi.org/10.1200/JCO.2004.03.137

30. Aaronson NK, Ahmedzai S, Bergman B, Bullinger M, Cull A, Duez NJ, Filiberti A, Flechtner H, Fleishman SB, Haes JCJM, Kaasa S, Klee M, Osoba D, Razavi D, Rofe PB, Schraub S, Sneeuw K, Sullivan M, Takeda F (1993) The European Organization for Research and Treatment of Cancer QLQ-C30: a quality-of-life instrument for use in international clinical trials in oncology. J Natl Cancer Inst 85(5):365-376

31. Sprangers MA, te Velde A, Aaronson NK (1999) The construction and testing of the EORTC colorectal cancer-specific quality of life questionnaire module (QLQ-CR38). European Organization for Research and Treatment of Cancer Study Group on Quality of Life. Eur J Cancer 35(2):238-247

32. Fayers PM, Aaronson N, Bjordal K, Groenvold M, Curran D, Bottomley A, on behalf of the EORTC Quality of Life Group (2001) The EORTC QLQ-C30 scoring manual (3rd edition). European Organisation for Research and Treatment of Cancer, Brussels

33. Osoba D, Rodrigues G, Myles J, Zee B, Pater J (1998) Interpreting the significance of changes in health-related quality-of-life scores. J Clin Oncol 16(1):139-144. https://doi.org/10.1200/JCO.1998.16.1. 139

34. Brandsma HT, Hansson BM, Aufenacker TJ, van Geldere D, Lammeren FM, Mahabier C et al (2017) Prophylactic mesh placement during formation of an end-colostomy reduces the rate of parastomal hernia: short-term results of the Dutch PREVENT-trial. Ann Surg 265(4):663-669. https://doi.org/10.1097/SLA. 0000000000001903

35. Fleshman JW, Beck DE, Hyman N, Wexner SD, Bauer J, George V, PRISM Study Group (2014) A prospective, multicenter, randomized, controlled study of non-cross-linked porcine acellular dermal matrix fascial sublay for parastomal reinforcement in patients undergoing surgery for permanent abdominal wall ostomies. Dis Colon Rectum 57(5):623-631. https://doi.org/10.1097/DCR. 0000000000000106

36. Hammond TM, Huang A, Prosser K, Frye JN, Williams NS (2008) Parastomal hernia prevention using a novel collagen implant: a 
randomised controlled phase 1 study. Hernia. 12(5):475-481. https://doi.org/10.1007/s10029-008-0383-Z

37. Târcoveanu E, Vasilescu A, Cotea E, Vlad N, Palaghia M, Dănilă N et al (2014) Parastomal hernias - clinical study of therapeutic strategies. Chirurgia (Bucur) 109(2):179-184

38. Serra-Aracil X, Bombardo-Junca J, Moreno-Matias J, Darnell A, Mora-Lopez L, Alcantara-Moral M, Ayguavives-Garnica I, Navarro-Soto S (2009) Randomized, controlled, prospective trial of the use of a mesh to prevent parastomal hernia. Ann Surg 249(4):583-587. https://doi.org/10.1097/SLA.0b013e31819ec809

39. Lambrecht JR, Larsen SG, Reiertsen O, Vaktskjold A, Julsrud L, Flatmark K (2015) Prophylactic mesh at end-colostomy construction reduces parastomal hernia rate: a randomized trial. Color Dis 17(10):O191-O197. https://doi.org/10.1111/codi.13065

40. López-Cano M, Lozoya-Trujillo R, Quiroga S, Sánchez JL, Vallribera F, Martí M, Jiménez LM, Armengol-Carrasco M, Espín E (2012) Use of a prosthetic mesh to prevent parastomal hernia during laparoscopic abdominoperineal resection: a randomized controlled trial. Hernia. 16(6):661-667. https://doi.org/10.1007/ s10029-012-0952-z

41. Vierimaa M, Klintrup K, Biancari F, Victorzon M, CarpelanHolmström M, Kössi J, Kellokumpu I, Rauvala E, Ohtonen P, Mäkelä J, Rautio T (2015) Prospective, randomized study on the use of a prosthetic mesh for prevention of parastomal hernia of permanent colostomy. Dis Colon Rectum 58(10):943-949. https:// doi.org/10.1097/DCR.0000000000000443

42. Herrle F, Sandra-Petrescu F, Weiss C, Post S, Runkel N, Kienle P (2016) Quality of life and timing of stoma closure in patients with rectal cancer undergoing low anterior resection with diverting stoma: a multicenter longitudinal observational study. Dis Colon Rectum 59(4):281-290. https://doi.org/10.1097/DCR. 0000000000000545

43. Brandsma HT, Hansson BM, Aufenacker TJ, van Geldere D, van Lammeren FM, Mahabier C et al (2016) Prophylactic mesh placement to prevent parastomal hernia, early results of a prospective multicentre randomized trial. Hernia. 20(4):535-541. https://doi. org/10.1007/s10029-015-1427-9

44. Lawday S, Leaning M, Flannery O, Bethune R (2018) Follow-up of the STOMAMESH cohort. Ann Surg 268:e30. https://doi.org/10. 1097/SLA.0000000000002786

45. Antoniou SA, Agresta F, Garcia Alamino JM, Berger D, Berrevoet F, Brandsma HT, Bury K, Conze J, Cuccurullo D, Dietz UA, Fortelny RH, Frei-Lanter C, Hansson B, Helgstrand F, Hotouras A, Jänes A, Kroese LF, Lambrecht JR, Kyle-Leinhase I, LópezCano M, Maggiori L, Mandalà V, Miserez M, Montgomery A, Morales-Conde S, Prudhomme M, Rautio T, Smart N, Śmietański M, Szczepkowski M, Stabilini C, Muysoms FE (2018) European Hernia Society guidelines on prevention and treatment of parastomal hernias. Hernia. 22(1):183-198. https://doi.org/10. 1007/s10029-017-1697-5

Publisher's note Springer Nature remains neutral with regard to jurisdictional claims in published maps and institutional affiliations. 